\title{
Influence of Polygonal Wear on Dynamic Performance of Wheels on High-Speed Trains
}

\author{
Ying SONG*, Xuemei ZHANG, Baochen SUN
}

\begin{abstract}
With increases in train speed and traffic density, polygonal wear of railway wheels arises accordingly, induced by the high impacts between wheels and rails, which is mainly related to operation safety and ride comfort of vehicle system. This work evaluates the effect of wheel polygon shape on the dynamic performance of the wheel set through numerical simulations. The finite element model, which includes the wheel set and the slab track, was established using ANSYS software to study the effects of polygonal wear on the dynamic behavior of the railway wheel. In the model, wheel-rail interaction forces caused by polygon wheel shape were solved using Universal Mechanisms of wear and were then entered into the finite element model. Using the simulation model, the influence of the harmonic order and out-of-roundness amplitude of wheel polygon on transient dynamic behaviors of the wheels namely, the displacement, acceleration, and von Misses equivalent stress were investigated. The results indicate that both the maximum dynamic displacement and Von Misses equivalent stress of the wheel plate show proportionality to the OOR amplitude, the harmonic order and the vehicle velocity. Besides, the maximum Von Misses equivalent stress occurs close to the wheel center, whereas the maximum displacement occurs close to the wheel tread. The findings will provide a theoretical basis for on-board detection methods of monitoring wheel polygonal wear.
\end{abstract}

Keywords: ANSYS finite element model; dynamic performance; high-speed railway; wheel polygon; wheel set

\section{INTRODUCTION}

Polygonal wheel wear is a type of long wavelength periodic wear around the circumference of railway wheels, which began to occur with the advent of high-speed trains. In high-speed operations, wheel polygonal wear leads to asymmetrical contact situations between the wheel and rail, making them unable to maintain the ideal state of symmetrical contact. Hence, the increasing dynamic impacts between wheels and rails have an adverse effect on the fatigue life of vehicle system components, threatening the operational safety and ride comfort in addition to bringing about rolling noise problems [1]. On June 3, 1998, the Inter City Express train derailment accident occurred due to wheel hub fracture induced by wheel polygonal wear. Eighty-eight people were injured and 101 people died because of this incident, with a total economic loss of about one billion Deutsche Mark.

Research into the causes of out-of-roundness (OOR) railway wheels reported aspects including inhomogeneous material properties of the wheel tread, faulty brake mechanisms, and dynamic motion of wheels in service [25]. However, there is currently no clear explanation as to the origins and the enlargement mechanisms for wheel polygonal phenomena. Refs. [6-10] reported the influence of wheel polygons on vehicle dynamic response and operation stability. The initiation and growth of OOR wheel defects and the damage they cause to the track and vehicle components were discussed in Refs. [11-15].

However, there is little research regarding the dynamic performance of the wheel induced by polygon wheel shape. The aim of this paper is to study the influence of polygon wheel shape on the dynamic displacement and stress of the wheels based on co-simulation using Universal Mechanism (UM) and ANSYS, to provide theoretical guidance as to the choice and optimal placement of sensors for on-board detection systems for polygonal wheel defects.

\section{SIMULATION MODELS}

In order to study dynamic behavior of wheels caused by polygonal wear, a three-dimensional (3D) finite element model including the wheel set and the slab track was developed using ANSYS software, as shown in Fig. 1. The China railways track structure II (CRTS II) slab ballastless track model is composed by $60 \mathrm{~kg} / \mathrm{m}$ rails, slab layer, rail fasteners, concrete/asphalt (CA) layer, and a support layer. It is assumed that the slab track is symmetric with respect to the centerline of the track, only half of the slab track was considered to reduce the simulation time and thus the computational cost. The $60 \mathrm{~kg} / \mathrm{m}$ rail was modeled by 3D solid finite element SOLID45. The concrete slab, concrete/asphalt layer, and support layer were all treated as elastic and were modeled by 3D solid finite element SOLID185. The connections between them were simulated with node freedom coupling technology. The rail fasteners were modeled as linear springs and dampers. The ends of the rail and the slab were constrained, as was the bottom of the support layer. Half of the wheel set was composed of the worn type wheel tread and the hollow axle, and divided by different size finite element meshes. The minimum size of the $3 \mathrm{D}$ element was $2.0 \mathrm{~mm}$ within $10^{\circ}$ around the circumference within the wheel and rail contact area, whereas the size of the other elements was $10 \mathrm{~mm}$. The parameters of the wheel set can be seen in Tab. 1. In view of the fact that the running distance of the wheel on the track is long, it is assumed that the wheel rotates mainly within a certain track section.

By combined simulation with multibody system dynamic simulation software Universal Mechanism (UM), taking polygonal wheels as input excitation, the harmonic periodic impacts induced by wheel polygonal wear were solved by a coupled vehicle/track dynamic model, and then entered into the ANSYS finite element model in the form of an array. The vehicle model consists of one vehicle body, two bogies and four wheel sets. The body and bogies are considered as rigid, including all rotational and translational degrees of freedom. Flexible wheel sets are built up in ANSYS environment and then coupled with the vehicle subsystem model in UM simulation software. The slab track model is implemented with UM Flexible Railway Track Module. Flexible slab track parameters, such as cross-sections of rails and their parameters, and vertical and lateral stiffness of the track, were consistent with those of finite element track model built in ANSYS as described above. For more details see Ref. [16]. 
Before performing transient dynamic analysis, a load step was first adopted to generate an initial displacement and stress. The maximum time interval was less than $10^{-4}$ s. The effects of track irregularities and other types of wheel damage on the dynamic performance of the wheels were not considered in this study.

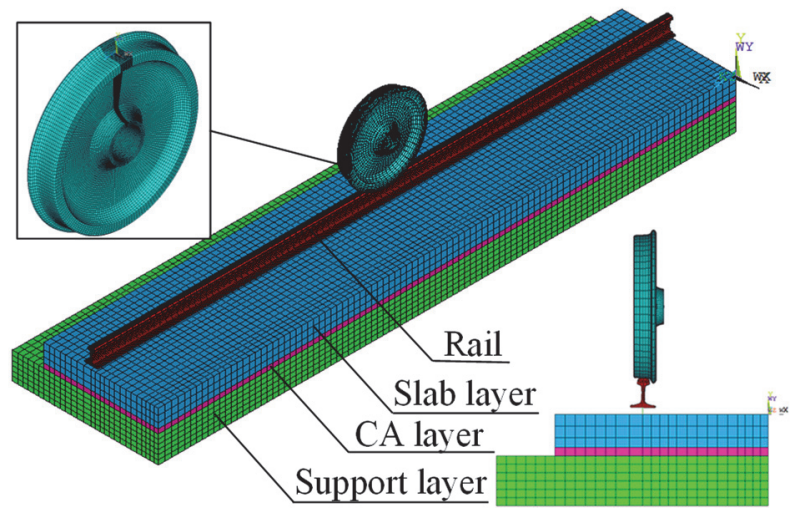

Figure 1 The finite element model of coupled wheel/track system

Table 1 Parameters of the wheel set

\begin{tabular}{|l|c|}
\hline \multicolumn{1}{|c|}{ Parameter } & Value \\
\hline Wheel diameter & $0.92 \mathrm{~m}$ \\
\hline Wheel inner diameter & $0.2 \mathrm{~m}$ \\
\hline Axle load & $14 \mathrm{t}$ \\
\hline Young modulus & $206 \mathrm{GPa}$ \\
\hline Poisson ratio & 0.29 \\
\hline Density & $7800 \mathrm{~kg} / \mathrm{m}^{3}$ \\
\hline
\end{tabular}

\section{RESULTS AND DISCUSSION}

In order to examine the influence of polygon wheel shape on the dynamic displacement and stress of the wheels three points located at different positions of the wheel plate are taken into account, as shown in Fig. 2.

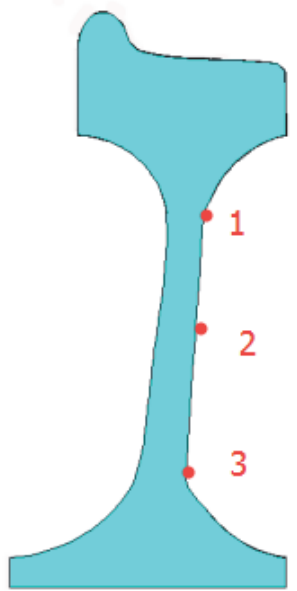

Figure 2 Positions of wheel plate considered for the calculation of the dynamic behavior

Simulation cases are shown in Tab. 2 .

Table 2 Simulation cases

\begin{tabular}{|c|c|c|c|}
\hline Cases & Speed $/ \mathrm{km} / \mathrm{h}$ & Harmonic order & OOR amplitude $/ \mathrm{mm}$ \\
\hline 1 & 300 & 6 & $\begin{array}{c}0.01,0.03,0.06, \\
0.09,0.12\end{array}$ \\
\hline 2 & 300 & $\begin{array}{c}3,6,9,11, \\
15,21\end{array}$ & 0.03 \\
\hline 3 & $200,250,300,350$ & 6 & 0.03 \\
\hline
\end{tabular}

\subsection{Effect of Amplitude of Wheel Polygon on Dynamic Performance of the Wheels}

The effects of the OOR amplitude of the sixth-order wheel polygon on the maximum dynamic displacement and Von Misses equivalent stress of the wheel plate at the speed of $300 \mathrm{~km} / \mathrm{h}$ are illustrated in Fig. 3 and Fig. 4, respectively. The polygonal wear amplitude varied between $0.01 \mathrm{~mm}$ and $0.12 \mathrm{~mm}$ with a step of $0.02 \mathrm{~mm}$. The results state that both the dynamic displacement and maximum Von Misses equivalent stress at the same position of the wheel plate show proportionality to the OOR amplitude; e.g., the maximum dynamic displacement of points on Ring 1 increases from $0.018 \mathrm{~mm}$ to $0.04 \mathrm{~mm}$ when the amplitude of polygonal wear increases from 0.01 $\mathrm{mm}$ to $0.12 \mathrm{~mm}$.

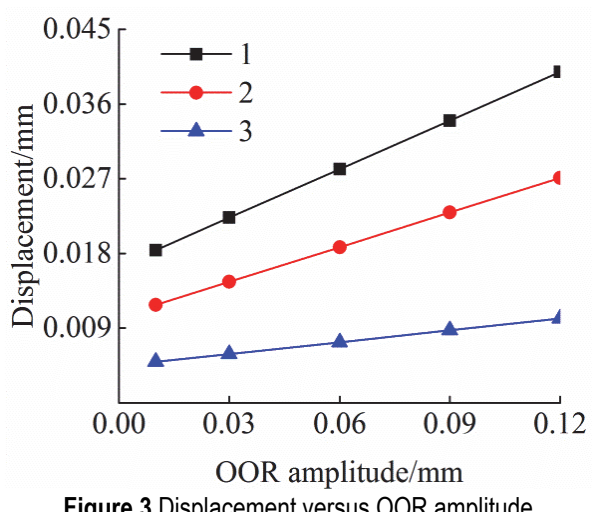

It can be seen from Fig. 3 that the displacement of points on Ring 1 is larger than other points in the same cross-section of the wheel plate; i.e., the closer to the wheel tread, the greater the displacement. The maximum displacements of points on Rings 1, 2, and 3 induced by the sixth-order wheel polygonal wear with $0.01 \mathrm{~mm}$ OOR amplitude are $0.018 \mathrm{~mm}, 0.012 \mathrm{~mm}$, and $0.005 \mathrm{~mm}$, respectively. The maximum displacement of points on Rings 1,2 , and 3, increases to $0.040 \mathrm{~mm}, 0.027 \mathrm{~mm}$, and $0.010 \mathrm{~mm}$, respectively, when the amplitude of polygonal wear increases to $0.12 \mathrm{~mm}$. This phenomena is because of the normal force variations induced by the change in OOR amplitude.

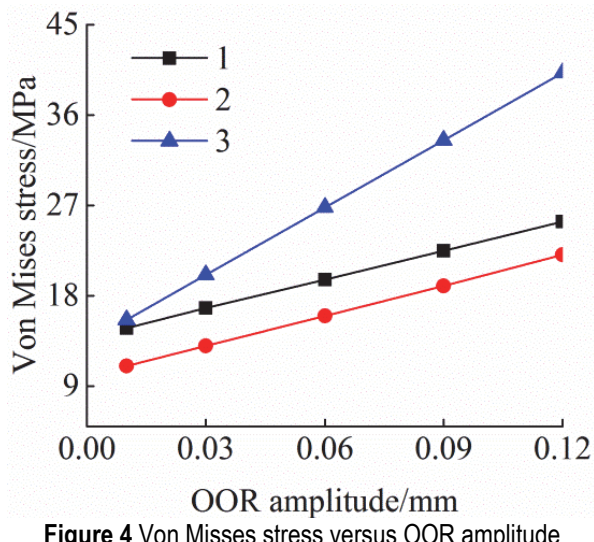

It is observed from Fig. 4 that the maximum Von Misses equivalent stress occurs close to the wheel center; i.e., the dynamic stress of points around the circumference 
of Ring 3 is larger than for Rings 1 and 2. In addition, the increases in amplitude of polygonal wear have greater influence on the dynamic stress of points located near the wheel center. This is because of the bending oscillation of the wheel set axle excited by vertical wheel displacement.

Fig. 5 shows the variations in dynamic displacement of the wheel plate induced by the wheel rotation. It can be observed that the waveform of displacement expresses the shape of a sinusoidal wave, including six wave lengths around the circumference of all three Rings on the wheel. It is induced by periodic irregularities along the wheel circumference, resulting in the variations of the wheel compression.
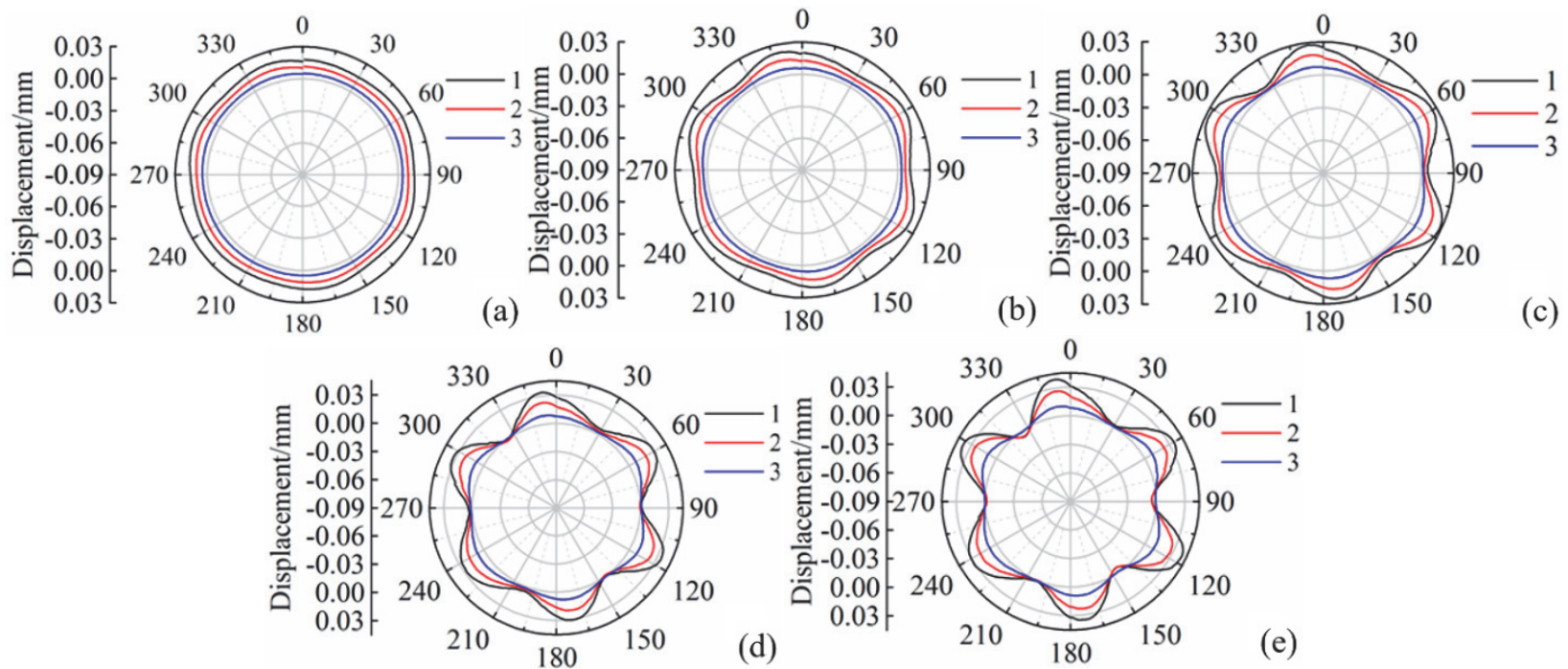

(d)

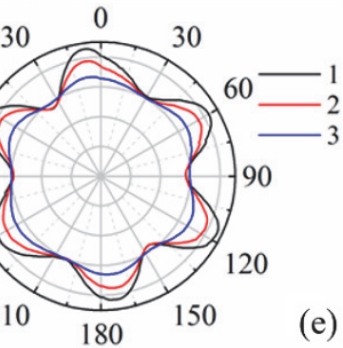

Figure 5 Displacement of the wheel in the polar coordinate system: a) OOR amplitude $0.01 \mathrm{~mm}$; b) OOR amplitude $0.03 \mathrm{~mm}$; c) $00 \mathrm{R}$ amplitude $0.06 \mathrm{~mm}$; d) OOR amplitude $0.09 \mathrm{~mm}$; e) OOR amplitude $0.12 \mathrm{~mm}$

The effect of the amplitude of wheel polygon on the maximum Von Misses equivalent stress for points around different rings of the wheel plate is demonstrated in Fig. 6. According to the comparison analysis of Fig. 6a-c, the dynamic stress of points around Ring 2 decreases gradually from the angle $0^{\circ}$ to $90^{\circ}$, and then increases slightly from the angle of $90^{\circ}$ to $180^{\circ}$. Whereas, the dynamic stress of points around Rings 1 and 3 decreases gradually from the angle of $0^{\circ}$ to $90^{\circ}$, and then increases obviously from the angle of $90^{\circ}$ to $180^{\circ}$. It implies that the minimum Von Misses equivalent stress occurred at an angle of $90^{\circ}$; this is because of the bending deflection of the wheel.
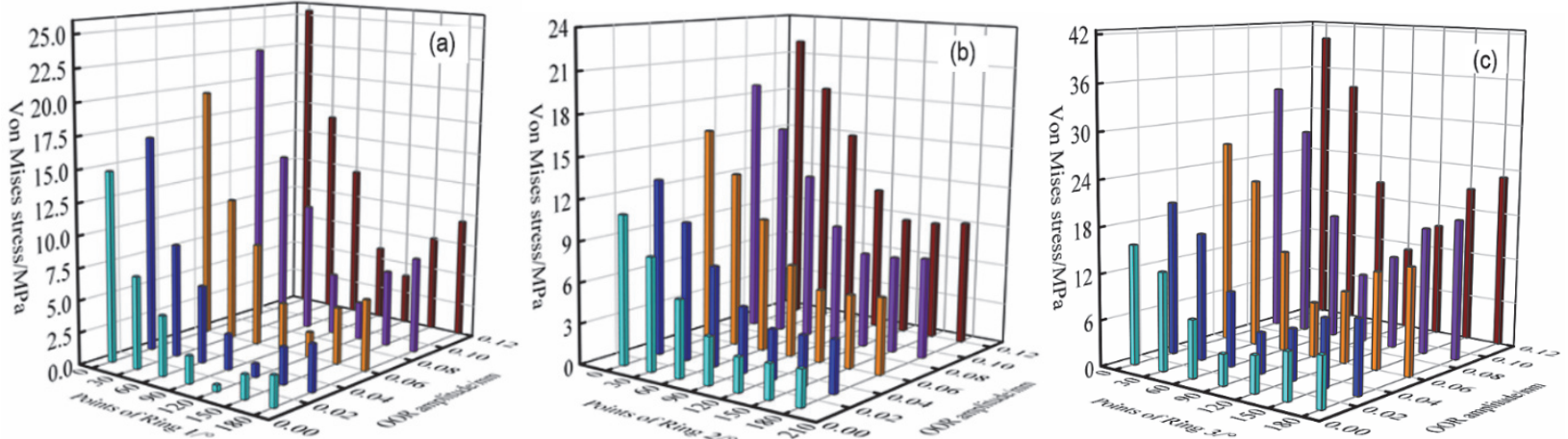

Figure 6 Influence of OOR amplitude on Von Misses equivalent stress of wheel plate: a) Von Misses equivalent stress of points around Ring 1; b) Von Misses equivalent stress of points around Ring 2; c) Von Misses equivalent stress of points around Ring 3

\subsection{Effect of the Order of Wheel Polygon on Dynamic Performance of the Wheels}

When a polygonal wheel with OOR amplitude of 0.03 $\mathrm{mm}$ runs on the track under the speed of $300 \mathrm{~km} / \mathrm{h}$, the effects of the harmonic order on the dynamic displacement and Von Misses equivalent stress of the wheel are illustrated in Fig. 7 and Fig. 8, respectively. As can be seen, the overall trend for both the displacements and Von Misses equivalent stresses is to increase as the harmonic order rises, for the points around the circumference of Rings 1, 2 and 3.

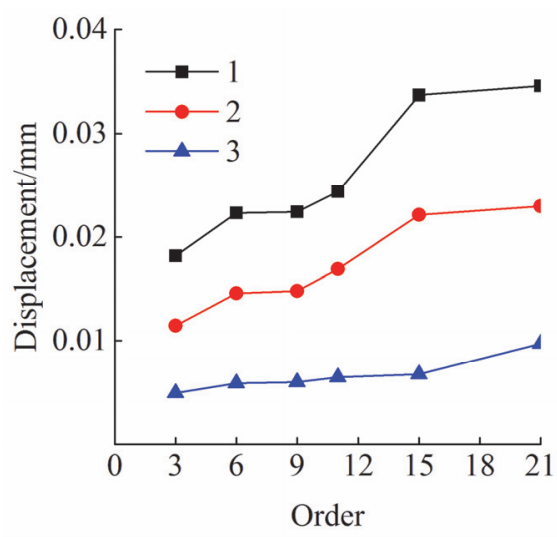

Figure 7 Displacement of the wheel versus harmonic order 
In Fig. 7 it is implied that, on the same cross-section of the wheel set, the dynamic displacement of points on Ring 1 is larger than that of Rings 2 and 3; i.e., the closer to the wheel tread, the larger the displacement. In addition, the dynamic displacement induced by high-order polygonal wear is larger than that caused by low-order polygonal wear; i.e., the maximum displacement induced by $21^{\text {st }}$ order polygonal wear reaches $0.031 \mathrm{~mm}$, which is approximately two times larger than the $0.016 \mathrm{~mm}$ for third-order polygonal wear. The reason is that the highorder polygonal wear induces high frequency wheel/rail contact vibration.

It can be deduced from Fig. 8 that the Von Misses equivalent stress induced by the harmonic order of wheel polygon increases sharply in the range between the $11^{\text {th }}$ and $21^{\text {st }}$ order. Moreover, the difference in the Von Misses equivalent stress for points on different Rings of the wheel plates increases; i.e., the maximum Von Misses equivalent stress of points on Ring 1 caused by the $21^{\text {st }}$ order polygonal wear reaches $34.56 \mathrm{kPa}$, approximately two times larger than the $16.3 \mathrm{kPa}$ for Ring 2 . It is mainly due to the wheel/track coupled vibration that becomes more dominating, as the harmonic order increases.

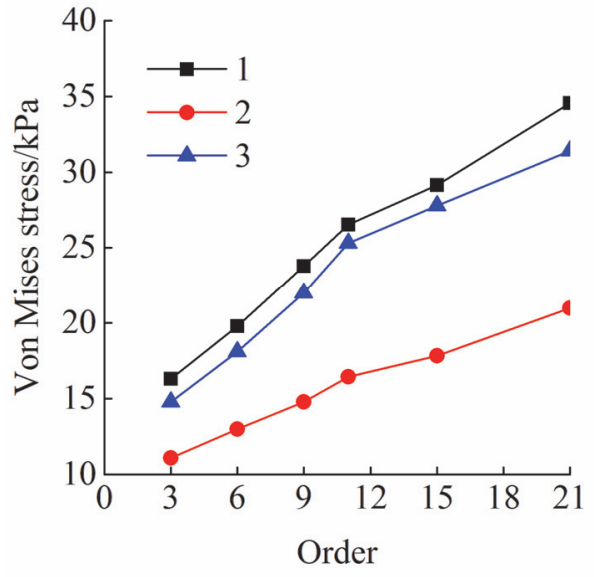

Figure 8 Von Misses stress of the wheel versus harmonic order
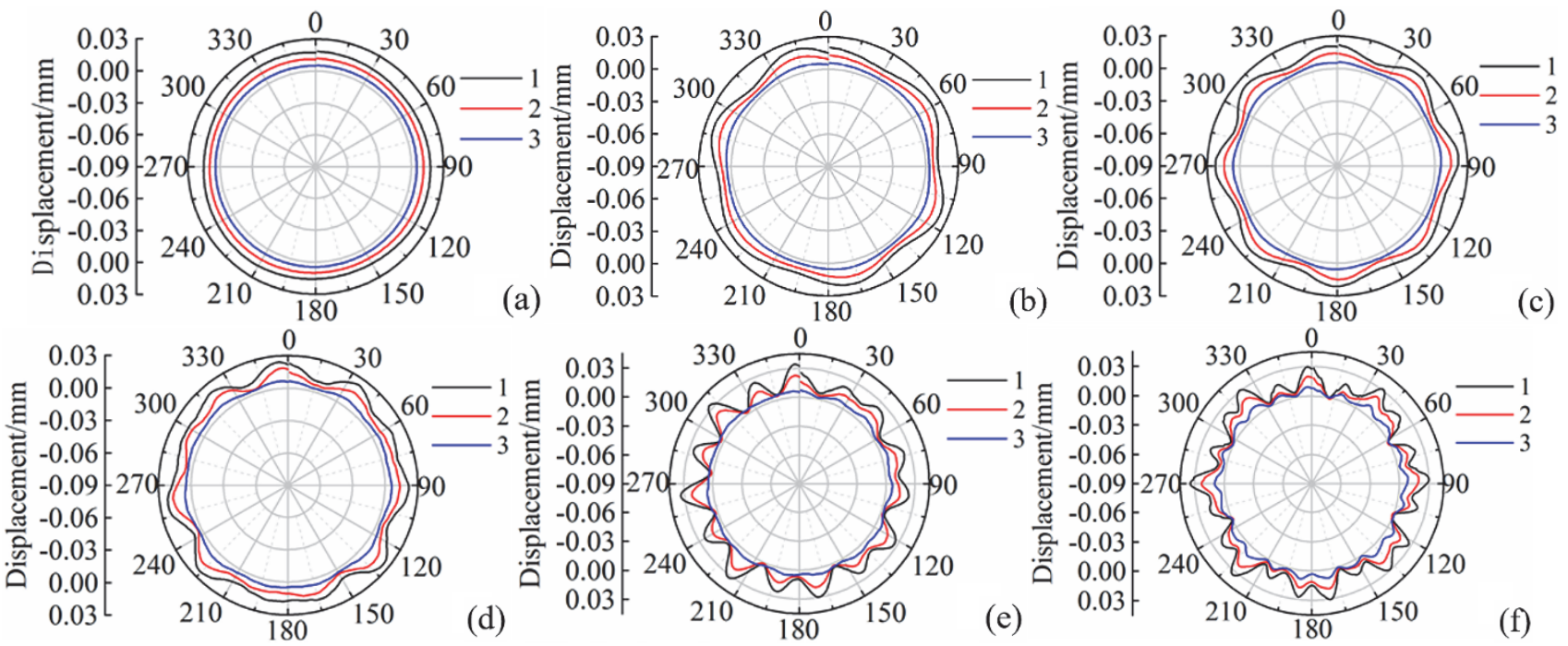

(c)

Figure 9 Displacement of the wheel in the polar coordinate system: a) $3^{\text {rd }}$ order; b) $6^{\text {th }}$ order; c) $9^{\text {th }}$ order; d) $11^{\text {th }}$ order; e) $15^{\text {th }}$-order; f) $21^{\text {st }}$ order
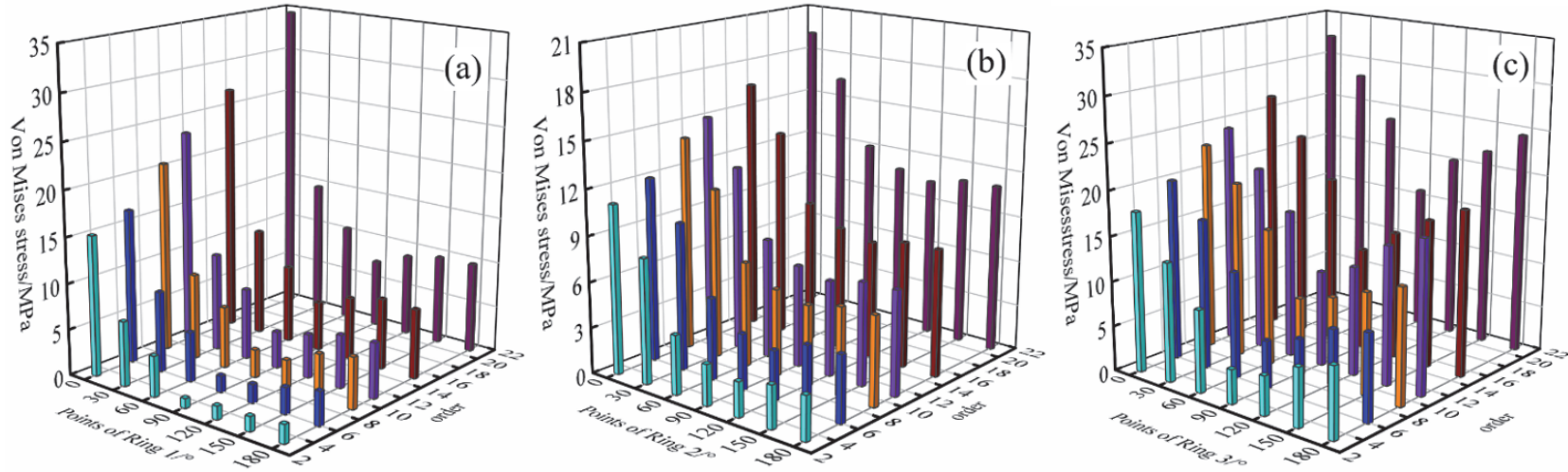

Figure 10 Influence of harmonic order on stress of the wheel: a) Von Misses equivalent stress of points around Ring 1; b) Von Misses equivalent stress of points around Ring 2; c) Von Misses equivalent stress of points around Ring 3

The influences of the harmonic order of wheel polygon on the dynamic displacement of the wheel plate induced by wheel rotation are illustrated in Fig. 9. It can be concluded that the waveforms of dynamic displacement follow a similar pattern to a sinusoidal wave, including $3^{\text {rd }}, 6^{\text {th }}, 9^{\text {th }}$, $11^{\text {th }}, 15^{\text {th }}$ and $21^{\text {st }}$ wavelengths around the circumference of all three rings. The variations of radial irregularity along the wheel circumference cause periodic impact loads and result in corresponding wheel compression.

Fig. 10 indicates the variations in Von Misses equivalent stresses for points on different rings of the wheel set with the increase of harmonic order, during the rotation of the wheel set. From comparisons of Fig. 10a-c, it is concluded that the maximum Von Misses equivalent stress of points around the circumferences of Ring 1 and 2 
decreases gradually from the angle of $0^{\circ}$ to $90^{\circ}$, and then increases slightly from the angle of $90^{\circ}$ to $180^{\circ}$. Whereas, the maximum Von Misses equivalent stress of points around the circumference of Ring 3 decreases sharply from the angle of $0^{\circ}$ to $90^{\circ}$, and then increases obviously from the angle of $90^{\circ}$ to $180^{\circ}$. The behavior of the wheel set depends mainly on large normal forces in the wheel/rail contact field.

\subsection{Effect of Train Speed on Dynamic Performance of the Wheels}

When the OOR amplitude is $0.03 \mathrm{~mm}$, the effect of train speed on the displacement and Von Misses equivalent stress of the wheel with sixth-order polygon shape is shown in Fig. 11 and Fig. 12, respectively.

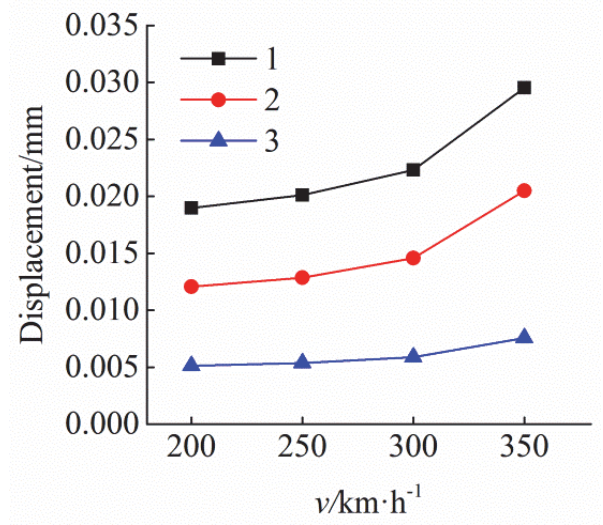

Figure11 Displacement of the wheel set versus train speed

Fig. 11 illustrates that the dynamic displacement at the same position of the wheel plate increases slightly in the range between $200 \mathrm{~km} / \mathrm{h}$ and $300 \mathrm{~km} / \mathrm{h}$, and then rises sharply between $300 \mathrm{~km} / \mathrm{hand} 350 \mathrm{~km} / \mathrm{h}$. That is, when the velocity increased from $200 \mathrm{~km} / \mathrm{h}$ to $350 \mathrm{~km} / \mathrm{h}$, the maximum dynamic displacement of points on Rings 1, 2, and 3 increased, respectively, by $32.47 \%, 40.40 \%$, and $28.13 \%$. It is also observed that for the same cross-section of the wheel plate, the dynamic displacement of Ring 1 is larger than that of the other two rings. Therefore, it can be concluded that the increase in velocity has important influence on the dynamic displacement of the wheel web.

In Fig. 12, it is observed that the Von Misses equivalent stress for points on Ring 1 and 2 increases slightly with increased speed. The Von Misses equivalent stress of points on Ring 3 increases slightly in the range between $200 \mathrm{~km} / \mathrm{h}$ and $300 \mathrm{~km} / \mathrm{h}$, and then rises markedly between $300 \mathrm{~km} / \mathrm{h}$ and $350 \mathrm{~km} / \mathrm{h}$. It implies that in the presence of wheel polygons, the increase in operating speed has great influence on the dynamic stress of points at the wheel spoke attached to the axle.

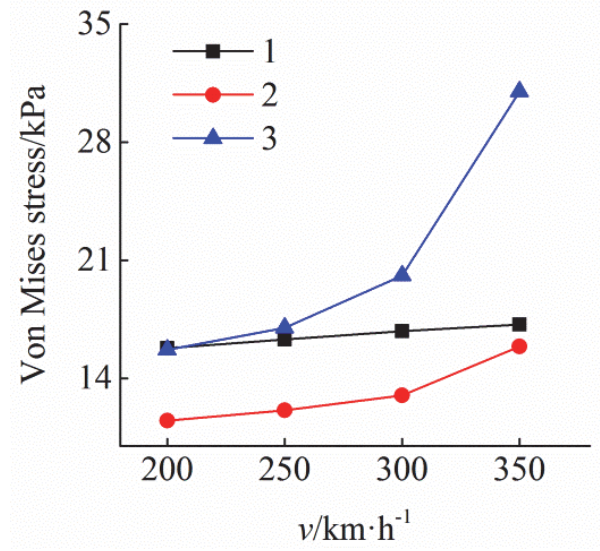

Figure 12 Von Misses equivalent stresses of the wheel set versus running speed

Fig. 13 shows dynamic displacements of points around the circumferences of Rings 1, 2, and 3 in the polar coordinate system with different velocity. It states that the waveform of dynamic displacement of all three rings shows the same shape as a sinusoidal wave, including six wavelengths around the circumference. The fluctuation amplitude of dynamic displacement increases as the velocity grows. This is because the exciting frequency of the wheel/rail coupled vibration rises, resulting in larger elastic deformation of the wheel.
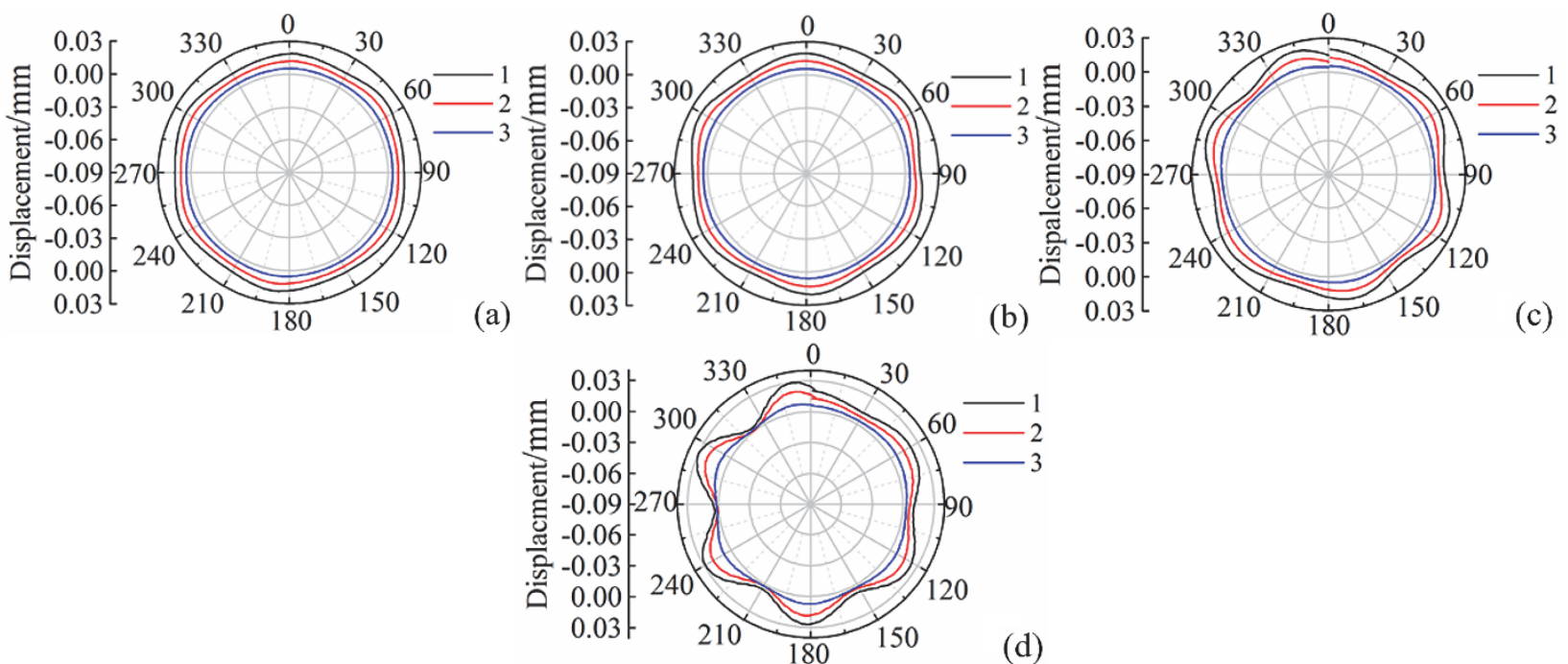

Figure 13 Dynamic displacements of points on Rings 1, 2, and 3 in the polar coordinate system: a) $200 \mathrm{~km} / \mathrm{h}$; b) $250 \mathrm{~km} / \mathrm{h}$; c) $300 \mathrm{~km} / \mathrm{h}$; d) $350 \mathrm{~km} / \mathrm{h}$

Fig. 14 illustrates the Von Misses equivalent stress for points on Rings 1, 2, and 3 as the operation speed grows.
As can be seen, Von Misses equivalent stress apparently rises with the increase of speed. When the speed remains 
unchanged, the Von Misses equivalent stress of points on Rings 1 and 3 first decreases and then increases, and the minimum stress is reached at the angle of $90^{\circ}$. Whereas, the Von Misses equivalent stress of points on Ring 2 gradually decreases from $0^{\circ}$ to $90^{\circ}$, and the change then flattens out from $90^{\circ}$ to $180^{\circ}$.
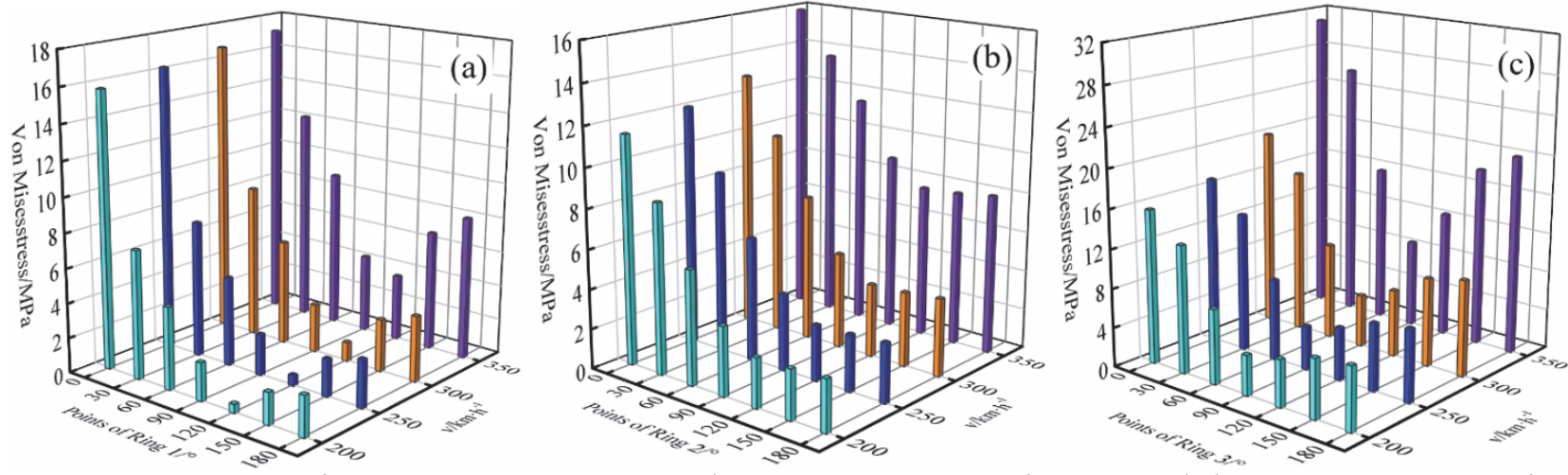

Figure 14 The Von Misses stress of the wheel plate versus running speed: a) Von Misses equivalent stress of points on Ring 1; b) Von Misses equivalent stress of points on Ring 2; c) Von Misses equivalent stress of points on Ring 3

\section{CONCLUSIONS}

The effect of polygon wheel shape on the dynamic performance of wheel set of high-speed train is investigated, based on ANSYS finite element analysis and Universal Mechanism dynamic simulation. Some conclusions have been drawn as follows.

Polygonal wears would cause variations in the dynamic displacement and stress of the wheel. Moreover, the overall trend of dynamic behavior of the wheel increases as the OOR amplitude and harmonic order and vehicle velocity rise, which deteriorates the safety of railway system components.

The maximum displacement occurs close to the wheel tread in the same cross-section of the wheel plate, i.e., the closer to the wheel tread, the greater the displacement. Nevertheless, the maximum Von Misses equivalent stress occurs close to the wheel center. In addition, the increases in amplitude of polygonal wear have greater influence on the dynamic stress of points located near the wheel center.

Both the dynamic displacement and the Von Misses equivalent stress induced by high-order polygonal wear are larger than those caused by low-order polygonal wear. Besides, the increase in vehicle velocity has great influence on the dynamic stress of points at the wheel spoke attached to the axle.

The variations of polygonal radial irregularity along the wheel circumference cause periodic impact load, and result in the waveforms of dynamic displacement and Von Misses equivalent stress follow a similar pattern to a sinusoidal wave.

Consequently, it is necessary to monitor the wheel shape on line and re-profile regularly to increase service life of the wheel set and reduce maintenance costs. However, the track is imperfect in actual engineering. Thus, the influence of both track irregularities and wheel damage on the behavior of the wheels is under investigation.

\section{Acknowledgements}

The authors thank for the support by the National Natural Science Foundation of China under grant 11372199, the Hebei Natural Science Foundation under grant E2019210152, and China Postdoctoral Science Foundation under Grant 2018M643521.

\section{REFERENCES}

[1] Meywerk, M. (1999). Polygonalization of railway wheels. Archive of Applied Mechanics, 69(2), 105-120. https://doi.org/10.1007/s004190050208

[2] Soua, B. \& Pascal, J. P. (1995). Computation of the 3D Wear of the Wheels in a High Speed Bogie. Report INRETS-LTN. Arcueil, 21-40.

[3] Brommundt, E. (1997). A simple mechanism for the polygonalization of railway wheels by wear. Mechanics Research Communications, 24(4), 435-442. https://doi.org/10.1016/S0093-6413(97)00047-5

[4] Dekker, H. (2009). Vibrational resonances of nonrigid vehicles: Polygonization and ripple patterns. Applied Mathematical Modelling, 33(3), 1349-1355. https://doi.org/10.1016/j.apm.2008.01.025

[5] Wu, X., Chi, M., \& Wu, P. (2015). Influence of polygonal wear of railway wheels on the wheel set axle stress. Vehicle System Dynamics, 53(11), 1535-1554. https://doi.org/10.1080/00423114.2015.1063674

[6] Nielsen, J. C. \& Johansson, A. (2000). Out-of-round railway wheels-a literature survey. Proceedings of the Institution of Mechanical Engineers, Part F: Journal of Rail and Rapid Transit, 214(2), 79-91. https://doi.org/10.1243/0954409001531351

[7] Hou, K., Kalousek, J., \& Dong, R. (2003). A dynamic model for an asymmetrical vehicle/track system. Journal of Sound and Vibration, 267(3), 591-604. https://doi.org/10.1016/S0022-460X(03)00726-0

[8] Barke, D. W. \& Chiu, W. K. (2005). A review of the effects of out-of-round wheels on track and vehicle components. Proceedings of the Institution of Mechanical Engineers, Part F: Journal of Rail and Rapid Transit, 219(3), 151-175. https://doi.org/10.1243/095440905X8853

[9] Zhang, X., Xiao, X., \& Jin, X. (2010). Effect of ovalization of high speed railway wheels on vehicle dynamic performance. Jixie Gongcheng Xuebao(Chinese Journal of Mechanical Engineering), 46(16), 67-73. https://doi.org/10.3321/j.issn:0577-6686.2008.03.009.

[10] Liu, X. \& Zhai, W. (2014). Analysis of vertical dynamic wheel/rail interaction caused by polygonal wheels on highspeed trains. Wear, 314(1-2), 282-290. https://doi.org/10.1016/j.wear.2013.11.048

[11] Johansson, A. (2005). Out-of-Round Railway WheelsCauses and Consequences an Investigation Including Field 
Tests, Out-of-Roundness Measurements and Numerical Simulations. German: Chalmers University of Technology. Books.

[12] Nielsen, J. C., Lundén, R., Johansson, A., \& Vernersson, T. (2003). Train-track interaction and mechanisms of irregular wear on wheel and rail surfaces. Vehicle System Dynamics, 40(1-3), 3-54. https://doi.org/10.1076/vesd.40.1.3.15874

[13] Johansson, A. \& Andersson, C. (2005). Out-of-round railway wheels - a study of wheel polygonalization through simulation of three-dimensional wheel-rail interaction and wear. Vehicle System Dynamics, 43(8), 539-559. https://doi.org/10.1080/00423110500184649

[14] Wu, Y., Du, X., Zhang, H. J. et al. (2017). Experimental analysis of the mechanism of high-order polygonal wear of wheels of a high-speed train. Journal of Zhejiang UniversitySCIENCE A, 18(8), 579-592. https://doi.org/10.1631/jzus.A1600741

[15] Morys, B. (1999). Enlargement of out-of-round wheel profiles on high speed trains. Journal of Sound and Vibration 227(5), 965-978. https://doi.org/10.1006/jsvi.1999.2055

[16] Song, Y., Du, Y. L., Zhang, X. M. et al. (2019). Evaluating the effect of wheel polygons on dynamic track performance in high-speed railway systems using co-simulation analysis. Applied Sciences, 9(19), 4165. https://doi.org/10.3390/app9194165

\section{Contact information:}

Ying SONG, PhD, Associate Professor (Corresponding author)

1) School of Traffic and Transportation, Shijiazhuang Tiedao University,

17 Northeast, Second Inner Ring, Shijiazhuang, Hebei, P.R.China 050043

2) School of Civil Engineering, Southwest Jiaotong University,

Chengdu 610031, P. R. China

\section{Xuemei ZHANG, MA. Eng}

Institution: School of Traffic and Transportation,

Shijiazhuang Tiedao University,

17 Northeast, Second Inner Ring, Shijiazhuang, Hebei, P.R. China 050043

Baochen SUN, MA. Eng, Professor

Structure Health Monitoring and Control Institute,

Shijiazhuang Tiedao University,

17 Northeast, Second Inner Ring, Shijiazhuang, Hebei, P.R. China 050043 